\title{
Dose Audits of Patients Undergoing Some Common Radiographic Examinations in Selected Nigerian Hospitals
}

\author{
Bamidele Lateef ${ }^{(1) \#}$, Osahon O. David ${ }^{(2)}$ \\ (1) Department of Science Laboratory Technology, Osun State, College of Technology, \\ Esa - Oke, Nigeria; (2)Department of Physics, University of Benin, Benin - City, \\ Nigeria.
}

\begin{abstract}
$\mathbf{T}$ HIS study aims at determining radiation doses for patients undergoing six (6) common radio graphic examinations in eight $\mathrm{X}$ - ray units in the southern part of Nigeria using computational method. Both public and private - owned hospitals were used for the study. Patient data and technical parameters were collected during the examinations. The mean entrance surface air kerma (ESAK) obtained from all the x-rays units considered ranged from 0.35 to $1.96 \mathrm{mGy}$ for Chest PA, 1.01 to $17.55 \mathrm{mGy}$ for Abdomen PA; 1.08 to $16.14 \mathrm{mGy}$ for pelvis AP,1.12 to $10.06 \mathrm{mGy}$ for Pelvis LAT, 0.08 to $3.54 \mathrm{mGy}$ for Skull AP/PA; 1.07 to 4.61 for Skull LAT, 1.67 to $12.46 \mathrm{mGy}$ for Lumber Spine AP, 1.82 to $14.24 \mathrm{mGy}$ for Lumber Spine LAT. Local diagnostic reference levels (LDRLs) were established based on the third quartile of ESAKs values. The established LDRLs were compared with previously established DRLs from other countries. The ESAKs values obtained in this study were found to be within the international established DRLs except in few cases.
\end{abstract}

Keywords: Entrance Surface Air Kerma, X-ray examinations, Dose optimization.

\section{Introduction}

Diagnostic X-ray remains the most commonly used tool in diagnosis both in developed and developing countries. It is the largest contributor to the population dose from man-made radiation source (Ajayi \& Akinwumiju, 2000; Johnston \& Brennan, 2000; Jones \& Wall, 1985 and Olowookere et al., 2012). Increase in the understanding of ionizing radiation health hazard nowadays has informed the need to carry out radiation assessment during diagnostic x-ray procedures. The need for assessment of patient doses in diagnostic radiology is widely accepted to ensure that doses are as low as reasonably achievable (CEC, 1996). Various patient dose surveys in different countries have been reported on the radiographic examinations frequencies, associated patient doses, comparison with diagnostic reference levels (Havukainen \& Pirinen, 1993; Veit et al., 1998; Tung et al., 2001; Ogundare et al., 2004; Oliveria et al., 2005; Gray et al., 2005; Obed et al., 2007 and Esen \& Obed 2012). The patient surveys provide important information on the levels of patient exposure and insight into causes of their variation.
Wide variations in patient dose undergoing the same type of x-ray examinations had been reported in various surveys (Shrimpton et al., 1986; Faulkner \& Corbelt, 1998; Hart et al., 2002; Gray et al., 2005 and Wall, 2005). These wide variations in patient dose are an indication that operational conditions were not fully optimized.In Nigeria, it was reported that there were over $4000 \mathrm{X}$-ray machines with less than 5\% under any form of regulatory control (Elegba, 2013 and Michael et al., 2016). A review of studies carried out in Nigeria for common X-ray examinations from 2000-2014 showed that there were significant dose variations for similar X-rays examinations (Akinlade et al., 2016). Also, the diagnostic reference levels (DRLs) which is an important mechanism for the management of patient dose to ensure it matches the medical purpose of X-ray examination, there is no evidence of published data indicating the establishment of DRLs in Nigeria (Olarinoye \& Sharifat, 2010 and Jibiri \& Olowooker, 2016). Therefore, there is a need for regular assessment of patient radiation doses arising from X-ray diagnostic examination. This study was conducted to assess the level of patients' radiation dose and to perform comparison with established diagnostic reference levels. 


\section{Materials and Method}

The study was conducted in eight (8) hospitals in three (3) states in the Southern part of Nigeria, and data were collected for seven hundred and twenty (720) patients. The hospitals included in the study were: Private Hospitals, State Hospitals, University Teaching Hospitals and a Federal Medical center.

Patient radiation dose assessment was conducted on patients who underwent Eight (8) common radiographic examinations: Chest Posterior - Anterior (PA), Lumbar Spine Anterior - Posterior (AP), Lumbar Spine Lateral (LAT), Pelvis (AP), Pelvis LAT, Abdomen (AP), Skull (AP/PA), Skull LAT.

Each X-ray unit was equipped with stationary, three phase 12-pulse or constant potential machine. Data based on the exposure parameters and patient characteristics such as tube potential $(\mathrm{kVp})$, focus-to-film distance (FFD), tube loading (mAs), filtration of the machine (inherent and added), exposed film area (assumed to be beam area), thickness of the exposed (irritated) part of the body, projections (e.g. AP, PA and LAT) were recorded during the routine exposure. Other patient anthropometrical data such as height, weight, sex and age of the patient were recorded at the time of the examination. The age groups included in this study ranged from 18-90 years.

\section{Quality Control Test of X-ray Machines}

The Quality Control (QC) test for each machine was carried out using QC kit $\left(\mathrm{NERO}^{\mathrm{TM}} 6000 \mathrm{~m}\right.$, manufactured by Victoreen, INC, Cleveland, Ohio, USA). The QC test was carried out by positioning the QC kit at the center of the beam axes at focus to image distance (FID) of $100 \mathrm{~cm}$ (Jibiri \& Olowookere, 2016). The QC tests carried out on each machine are: the $\mathrm{kVp}$ parameters (accuracy, reproducibility and consistency), the exposure time (including reproducibility and accuracy) and the output of the machines (including linearity coefficient and output reproducibility).

\section{Entrance Surface air Kerma (KERMA) Measurement}

According to the International Atomic Energy Agency (IAEA) Code of Practice, there are principal dosimetric quantities to be measured in general radiography, they are: incident air kerma $\left(\mathrm{k}_{\mathrm{i}}\right)$, the entrance surface air kerma (ESAK) and the air kerma - area product (IAEA, 2007). The entrance surface airkerma is defined as the kerma to air measured on the central beam axis at the position of the patient or phantom inclusive of the backscattered radiation.

In this study, indirect method of assessing patient dose through the evaluation of entrance surface air kerma (ESAK) from measured X-ray exposure factors $(\mathrm{kVp}, \mathrm{mAs}, \mathrm{FFD})$ using the semi empirical formular as recommended by IAEA protocol and code of practice (IAEA, 2007). The ESAK value is obtained using the empirical formular:

$$
\mathrm{ESAK}=\mathrm{Y}(\mathrm{d}) \times \mathrm{mAs} \times\left[\frac{d}{F F D-t_{p}}\right]^{2} \times \mathrm{BSF}
$$

where $\mathrm{Y}(\mathrm{d})$ is the $\mathrm{X}$-ray tube output at distance $100 \mathrm{~cm}$ normalized by $10 \mathrm{~m} \mathrm{As,} \mathrm{FFD} \mathrm{is} \mathrm{the} \mathrm{focus-}$ film-distance, where, $t_{p}$ is the patient thickness and BSF is the backscatter factor, which depends on tube potential, device filtration and the size of radiation field (ICRU, 2005 and IAEA, 2007).

\section{Experimental verification}

To show that the computational method employed in this study was in agreement with direct practical measurements, the ESAK values obtained were compared with direct patient doses measurement using thermolumnescent dosemeters (TLD) chips attached to the patient's body at the center of X-ray field. The comparison of the data obtained from computational method and the direct measurement using TLD were done using statistical tool. The TLD used were calibrated using facilities of National Institute For Radiation Protection and Research (NIRPR) at University of Ibadan, Nigeria. X-ray beam irradiator was used to irradiate the chips. The chips were placed at $2 \mathrm{~m}$ distance from the source against a water phantom and irradiated. Element correction coefficient (ECC) and reader calibration factors (RCF) were calculated during the calibration using Harshaw TLD Reader Model 4500 and WinRems Software. The calibrated TLD chips were annealed under the temperature of $400^{\circ} \mathrm{C}$ for $1 \mathrm{hr}$ and allowed to cool down in the oven for $18 \mathrm{hr}$.

Three chips were sealed in thin black polythene, coded for proper identification, before being placed on the patient's skin surface. The chips after exposure, were read using a Victoreen (2800M) TLD reader at the Center for Energy Research and Development, Obafemi Awolowo 
University, Ile-Ife, Nigeria. The response of the thermoluminescent reader for each chip was converted to dose using the appropriate calibration factor already obtained.

\section{Results and Discussion}

This study was carried out in eight X-ray units in the southern part of Nigeria. The $\mathrm{X}$-ray machine model, manufacture, year of installation, filtration of machines and tube output $(\mathrm{mGy} / \mathrm{mAs})$ was shown in Table 1 . The filtration of two machines fall short of required standard of $2.5 \mathrm{~mm} \mathrm{Al}$ recommended for machine operating above $75 \mathrm{kV}$. Low filtration leads to higher doses since low energy X-rays of energy level below $40 \mathrm{keV}$ is not used for diagnostic imaging but it increases patient doses.

Table 2 shows the results of quality control of the X-ray machines in all the units. The $\mathrm{kVp}$ accuracy should not beyond $\pm 5 \%$ and the reproducibility and consistency should not exceed $10 \%$. The $\mathrm{kVp}$ accuracy calculated ranged from $0.32 \%$ to $0.96 \%$ which was lower than the tolerance limit. The $\mathrm{kVp}$ reproducibility and consistency ranged from $0.14 \%$ to $0.65 \%$ and $0.30 \%$ to $0.95 \%$, respectively. It can be seen from Table 2 that the accuracy and reproducibility of exposure time were up to standard in all X-ray units. Also, the coefficient of output linearity and the reproducibility of the machines in all X-ray units were up to standard recommended by the American Association of Physicists in medicine (AAPM, 2002).

Summaries of the mean and range of the patient's age, patient's weight, focus-to-film distance (FFD), tube potential $(\mathrm{kVp})$, and tube load (mAs) were presented in Table 3. The FFD employed in the examinations in some cases were outside recommended criteria by Committee of the European Communities (CEC).A comparison of mean $\mathrm{kVp}$ values in this study with UK data shows that the mean values are comparable in pelvis AP and lumbar spine AP.

Summaries of the mean and range of the patient's age, patient's weight, focus-to-film (FFD), tube potential $(\mathrm{kVp})$, and tube load (mAs) were presented in Table 3. The FFD employed in the examinations in some cases were outside recommended criteria by Committee of the European Communities (CEC):A comparison of mean $\mathrm{kVp}$ values in this study with UK data shows that the mean values are comparable in pelvis AP and lumbar spine AP.

TABLE 1. Specific features of units in the investigated center.

\begin{tabular}{|c|c|c|c|c|c|}
\hline Hospitals & $\begin{array}{l}\text { Model/ } \\
\text { Type }\end{array}$ & Manufacturer & $\begin{array}{l}\text { Year of } \\
\text { Installation }\end{array}$ & $\begin{array}{l}\text { Filtration } \\
\text { (mmAl) }\end{array}$ & $\begin{array}{l}\text { Output } \\
\text { ( } \mu \mathrm{Gy} / \mathrm{mAs})\end{array}$ \\
\hline$\overline{\text { OAUTHC }}$ & Silhouette & G.E Haulum & & & \\
\hline Ilesa & V.R & Medical System & 2010 & 2.7 & 61.00 \\
\hline OAMH & LEXRAY & R. Liecati A. G R. & & & \\
\hline Ilesa & 500 & Liecati A. E & 2013 & 3.0 & 65.00 \\
\hline $\begin{array}{l}\text { UTH, } \\
\text { Ado-Ekiti }\end{array}$ & Allengers & N A & 2012 & 2.5 & 35.00 \\
\hline FMC & Giladonia & & & & \\
\hline Ido-Ekiti & Ri05 & Ralco & 2013 & 2.0 & 34.70 \\
\hline ADC, Ilesa & Ketron 300 & $\begin{array}{l}\text { Kehrli } \\
\text { Rontgen Inc. }\end{array}$ & 2013 & 2.5 & 48.00 \\
\hline $\mathrm{CH}$ & & Siemens & & & \\
\hline Benin - City & Siemens & Healthineers USA & NA & 3.0 & 34.00 \\
\hline $\begin{array}{l}\text { LTH } \\
\text { Osogbo }\end{array}$ & $\begin{array}{l}\text { Toshiba } \\
\text { Rotande }\end{array}$ & $\begin{array}{l}\text { Toshiba medical } \\
\text { system }\end{array}$ & 2014 & 2.5 & 32.00 \\
\hline $\begin{array}{l}\text { UBTH } \\
\text { Benin-City }\end{array}$ & RAD-12 G.E & $\begin{array}{l}\text { General Electric } \\
\text { Company }\end{array}$ & 2010 & 1.6 & 68.00 \\
\hline
\end{tabular}


TABLE 2. The results of Quality Control test of the X- ray units.

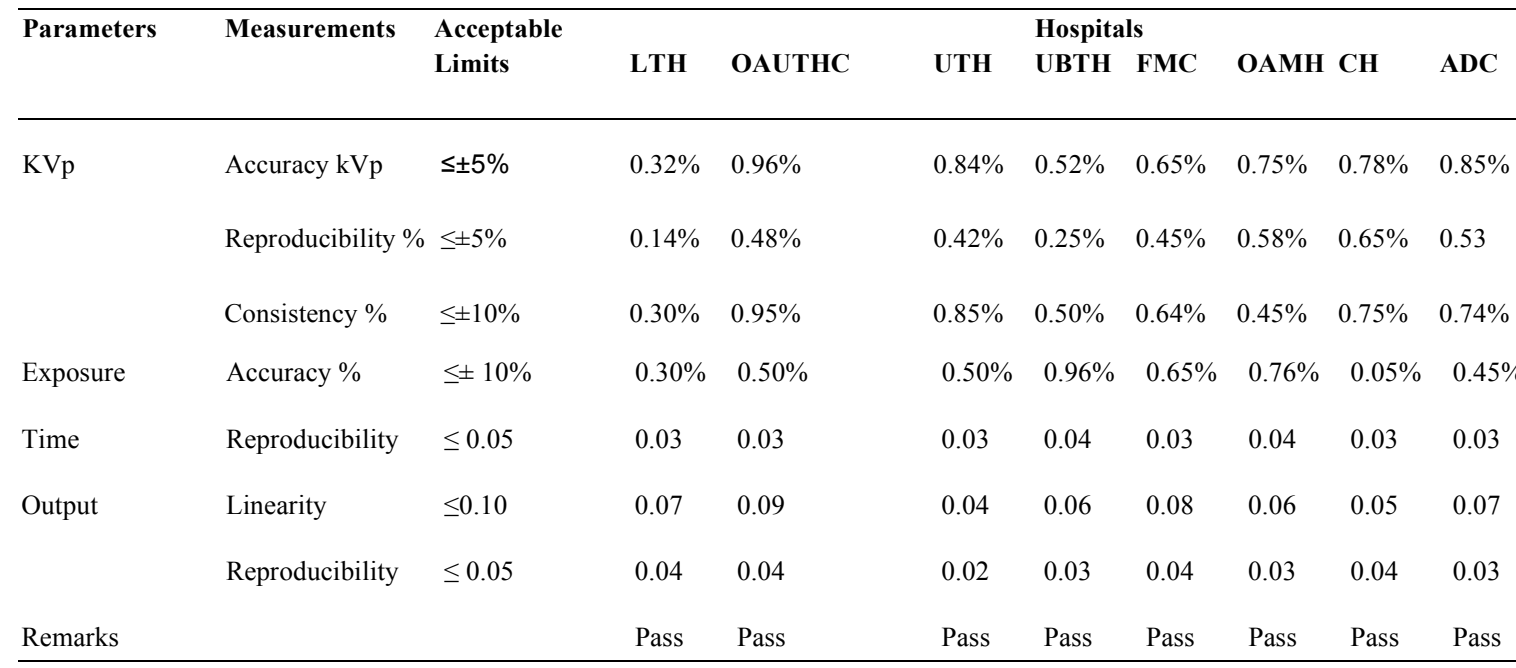

TABLE 3. Patient information exposure parameters for eight routine examinations mean values and range in all $\mathrm{X}$ - ray units.

\begin{tabular}{|c|c|c|c|c|c|c|c|c|}
\hline Examinations & Projection & $\begin{array}{l}\text { No. of } \\
\text { Patients }\end{array}$ & $\begin{array}{l}\text { Patient age } \\
\text { mean } \\
\text { (range) } \\
\text { (years) }\end{array}$ & $\begin{array}{l}\text { Patient } \\
\text { weight } \\
\text { mean } \\
\text { (range) kg }\end{array}$ & $\begin{array}{l}\text { FFD } \\
\text { mean } \\
\text { (range) } \\
(\mathrm{cm})\end{array}$ & $\begin{array}{l}\text { kVp } \\
\text { mean } \\
\text { (range) }\end{array}$ & $\begin{array}{l}\text { mAs } \\
\text { mean } \\
\text { (range) }\end{array}$ & $\begin{array}{l}\text { KVp UK } \\
\text { Hart et al } \\
(2012)\end{array}$ \\
\hline Chest & PA & 276 & $42(20-80)$ & $67(67-72)$ & $149(90-182)$ & $69(57-80)$ & $25(10-40)$ & $88(65-125)$ \\
\hline Abdomen & AP & 75 & $63(49-79)$ & $70(68-72)$ & $124(70-131)$ & $81(80-81)$ & $49(40-64)$ & $76(60-94)$ \\
\hline Pelvis & $\mathrm{AP}$ & 74 & $42(19-70)$ & $69(68-84)$ & $118(80-124)$ & $75(55-81)$ & $40(25-63)$ & $75(62-92)$ \\
\hline Pelvis & LAT & 64 & $40(19-70)$ & $68(69-72)$ & $115(80-125)$ & $73(60-81)$ & $36(10-50)$ & NA \\
\hline Skull & $\mathrm{AP} / \mathrm{PA}$ & 60 & $38(30-45)$ & $71(70-74)$ & $112(70-153)$ & $74(70-80)$ & $38(32-40)$ & $72(69-83)$ \\
\hline Skull & LAT & 56 & $39(30-46)$ & $70(61-74)$ & $110(70-150)$ & $72(63-85)$ & $28(25-32)$ & NA \\
\hline Lumbar Spine & AP & 58 & $75(38-90)$ & $67(60-75)$ & $117(90-160)$ & $78(73-96)$ & $91(40-125)$ & $78(65-109)$ \\
\hline Lumbar Spine & LAT & 57 & $75(38-90)$ & $67(60-75)$ & $114(90-130)$ & $90(81-96)$ & $110(64-125)$ & NA \\
\hline
\end{tabular}

Table 4 shows the mean of ESAKs and corresponding standard error on mean (SEM) of each ESAK. From the Table, it can be seen that there are wide variations on the ESAK values for the same type of projections in different X-ray units. The variations in the ESAK values are due to patient sizes, radiographic equipment used and most especially the radiographic technique adopted by the radiographer.

In Table 5, a comparison between ESAKs obtained in this work with some published international established reference dose levels (DRLs) is shown. A comparison of the ESAK values in this work with those from IAEA, NRPB and Brazil reference value shows that $75 \%$ of the hospitals have dose higher than the correspondence reference values for Chest
PA. For Abdomen AP, $37.5 \%$ of the hospitals have higher dose than international established reference dose in Abdomen projection. Also, $87.5 \%$ have lower ESAK value compare with the DRLs recommended by NRPB and IAEA for Pelvis AP. Furthermore, $50 \%$ of the hospitals have greater dose values for skull PA and lumbar spine AP than corresponding guidance levels, All the hospitals have higher ESD value for Skull LAT when compared with dose reference value recommended by NRPB but only $\mathrm{CH}$, Benin-City have ESAK value of $18.35 \mathrm{mGy}$ higher for lumbar spine AP when compared with corresponding reference value of $5.7 \mathrm{mGy}$ recommended by NRPB.

Table 6 shows statistical data of the analysis of correlation between measured value and 
estimated value from computational method. For chest PA, it is observed that $\mathrm{R}=0.9975$ and $\mathrm{R}^{2}=0.9951$ indicate a very high correlation measures. Therefore, there is a very high degree of relationship between the values of patient dose measured with TLDs and those calculated using computational method. Also, for abdomen AP, pelvis AP/LAT and skull AP/PA, $\mathrm{R}=0.9996, \mathrm{R}^{2}=$ 0.9991; $\mathrm{R}=0.9987, \mathrm{R}^{2}=0.9974$ and $\mathrm{R}=0.9996$,
$\mathrm{R}^{2}=0.9992$, respectively, which are indication of a very high correlation measures. Therefore, it can be concluded that there is a very high degree of relationship between the dose values measured with TLDs and those calculated using computational method. The statistical analysis of the data showed that the measured and calculated doses were not significantly different.

TABLE 4. Mean ESAK (mGy) for each X- ray unit and corresponding standard error on mean (SEM).

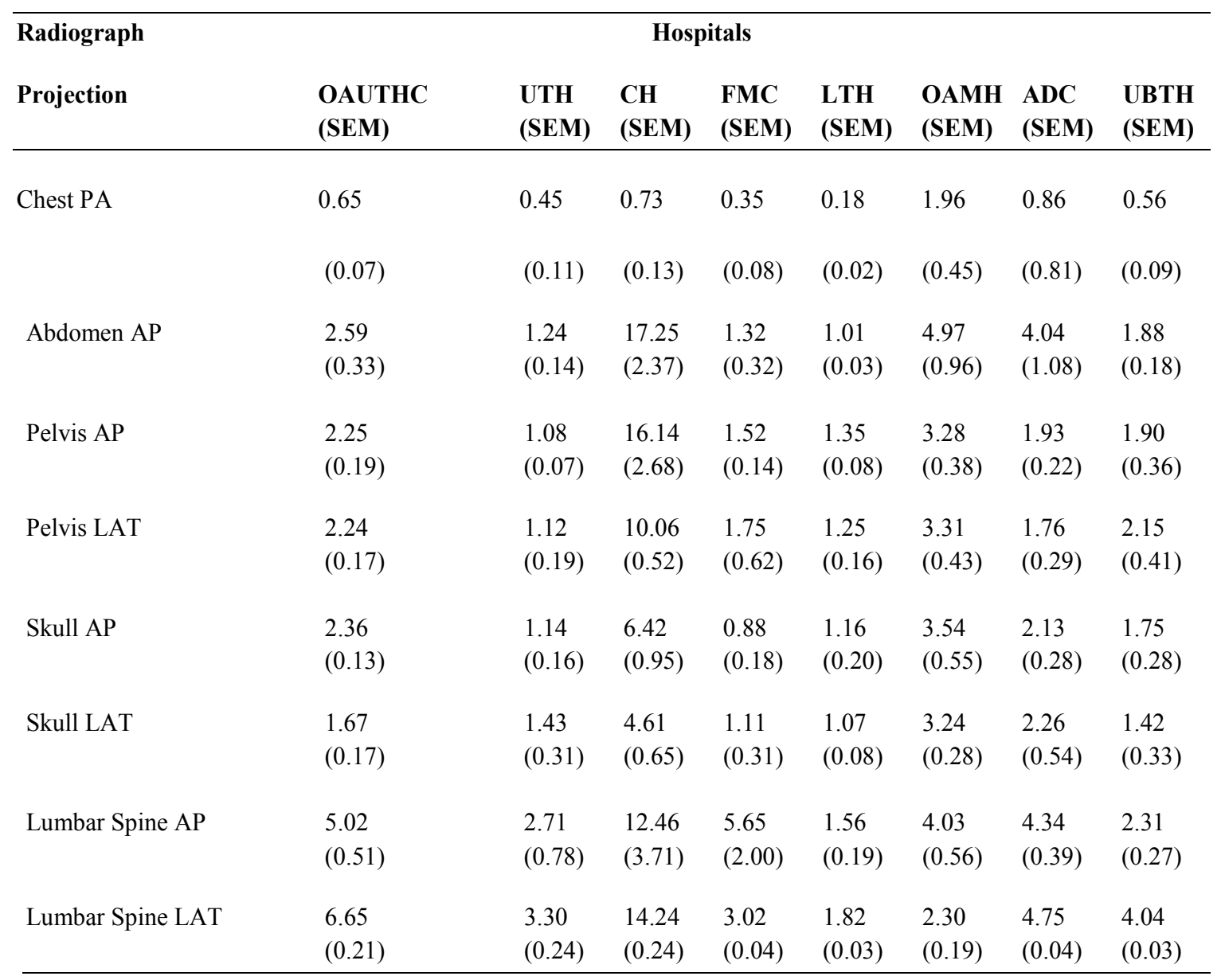

\section{Conclusion}

Entrance surface air kerma (ESAK) of 720 patients in eight X-ray centers across 3 states in the southern part of Nigeria have been evaluated. The intra- and inter- hospital dose variations of the same type of projections were established in the study. The wide variations in ESAK values for the same type of examinations obtained in this study show that the radiographic technique employed were not fully optimized and machines used were not better monitored. This points to the fact that there is a serious need to institute programs and monitoring, aiming at reducing patient dose in Nigeria. These may include organization of conferences, workshops and inservice training for radiographer and radiologist, so they can be aware of latest developments in the field. Further dose surveys in the area of diagnostic radiology that will eventually lead to a possible establishment of National dose reference levels (NDRLs) should be encouraged. 
TABLE 5. A comparison of Third Quartile of Dose Audit (ESAK) in this study with DRLs and International Recommendations.

\begin{tabular}{|c|c|c|c|c|c|c|c|c|c|c|c|c|}
\hline \multirow{2}{*}{$\begin{array}{l}\text { Radiograph } \\
\text { Projection }\end{array}$} & \multirow{2}{*}{\multicolumn{2}{|c|}{ OAUTHC UTH }} & \multirow[b]{2}{*}{$\mathbf{C H}$} & \multicolumn{5}{|c|}{ Hospital } & \multicolumn{4}{|l|}{ DRLs } \\
\hline & & & & FMC & LTH & ОАМН & ADC & UBTH & IAEA $^{\mathrm{a}}$ & NRPB ${ }^{b}$ & NIGERIA $^{\mathrm{C}}$ & BRAZIL $^{d}$ \\
\hline & & & & & & & & & 2008 & 2010 & 2016 & 2009 \\
\hline Chest PA & 0.13 & 0.36 & 0.68 & 0.49 & 0.13 & 2.57 & 0.92 & 0.61 & 0.33 & 0.15 & 2.95 & 0.33 \\
\hline Abdomen AP & 1.04 & 1.49 & 21.13 & 1.96 & 1.04 & 5.82 & 5.33 & 2.18 & 3.64 & 4.4 & 22.31 & 3.64 \\
\hline Pelvis AP & 1.47 & 1.20 & 20.21 & 1.07 & 1.47 & 3.04 & 2.27 & 2.18 & 3.68 & 3.9 & 6.63 & 3.68 \\
\hline Pelvis LAT & 1.50 & 1.42 & 16.384 & 2.49 & 1.50 & 3.90 & 1.98 & 2.56 & NA & NA & NA & NA \\
\hline Skull AP & 1.50 & 1.35 & 6.99 & 1.27 & 1.50 & 3.76 & 2.52 & 2.18 & NA & 1.8 & 9.04 & NA \\
\hline Skull LAT & 1.199 & 1.74 & 5.32 & 1.12 & 1.199 & 3.45 & 2.74 & 2.18 & NA & 1.1 & NA & NA \\
\hline Lumbar Spine AP & 1.97 & 3.72 & 16.38 & 7.38 & 1.97 & 4.82 & 4.72 & 2.81 & 4.07 & 5.7 & 5.87 & 4.07 \\
\hline Lumbar Spine LA & $\mathrm{AT} 2.41$ & 3.54 & 18.35 & 3.31 & 2.41 & 4.79 & 5.74 & 4.35 & NA & 10 & NA & NA \\
\hline
\end{tabular}

NA : Not Avaliable; $\quad{ }^{\mathrm{a}}$ Muhogora et al. (2008), ${ }^{\mathrm{b}} \mathrm{Hart}$ et al. (2002), ${ }^{\mathrm{C} J i b i r i ~ \& ~ O l o w o o k e r e ~(2016), ~}{ }^{\mathrm{d}}$ Freitas \& Yoshimura (2009).

TABLE 6. Statistical Data of the Analysis of Correlation between measured value and estimated value from computational method.

\begin{tabular}{lllll}
\hline Examinations & Chest PA & Abdomen AP & Pelvis AP/LAT & Skull AP/PA \\
\hline n Pairs & 74 & 14 & 30 & 12 \\
Pearson Correlation (r) & 0.9975 & 0.9996 & 0.9987 & 0.9996 \\
$95 \%$ C I & $0.9961-0.9985$ & $0.9986-0.9999$ & $0.9972-0.9994$ & $0.9986-0.9999$ \\
P Value (2- tailed) & $<0.0001$ & $<0.0001$ & $<0.0001$ & $<0.0001$ \\
Significance of Correlation & Yes & Yes & Yes & Yes \\
$\mathrm{R}^{2}$ & 0.9951 & 0.9991 & 0.9974 & 0.9992 \\
\hline
\end{tabular}

\section{Reference}

AAPM (2002) American Association of Physicists in Medicine: Quality Control in Diagnostic Radiology. AAPM Report No. 74. Madison: Medical Physics Publishing.

Ajayi, I.R. and Akinwumiju, A. (2000) Measurement of entrance skin dose to patients in four common diagnostic examinations by thermoluminscence dosimetry in Nigeria. Radiat. Prot. Dosim. 87, $217-$ 220 .

Akinlade, B.I., Odefemi, F.B. and Farai, I.P. (2016) Overview of radiation dose to patient from medical examinations in Nigeria. Afr. J. Med. Sci. 45, 23-29.

CEC (1996) European Guidelines on Quality Criteria Diagnostic Radiographic Images EUR 16260 EN. CEC Brussels.

Elegba, S.B. (2013) Radiation Safety Officer (RSO) in
Diagnostic and Interventional Radiology. Keynote Address, University of Ibadan, Nigeria. Available from: http//www.archive.punchontheweb. com/ article.aspx \. [Last updated on 2013 Dec 11].

Esen, N.U. and Obed, R.I. (2012) Doses received by Patients during Thorax X-ray examinations. Iranian Journal of Medical Physics, 9(4), 245-251.

Faulkner and Corbelt (1998) Reference dose and quality in medical imaging. Br. Radiol. 71, 4001-2.

Freitas, M.B. and Yoshimura, E.M. (2009) Diagnostic reference levels for the most frequent radiological examinations carried out in Brazil. Public Health, 25(2), 95-104.

Gray, J.E., Archer, B.R. and Butles, P.F., et al. (2005) Reference values for diagnostic radiology: application and impact. Radiology, 235, 354-358.

Hart, D., Hillier, M.C. and Wall B.F. (2002) Doses to 
patients from medical X-ray examinations in the UK Review, National Radiological Protection Board NRPB - W 14 Oxfordshire, United Kingdom.

Havukainen, R. and Pirinen, M. (1993) Patient dose and image quality in 5 Standard X-ray examinations. Med.Phys. 20, 813-817.

IAEA (2007) International Atomic Energy Agency. Technical Report Series Number 457, Dosimetry in Diagnostic Radiology: An International Code of Practice. IAEA, Vienna.

ICRU (2005) Patient Dosimetry for X-rays used in medical Imaging. International Commission on Radiation Units and Measurements publications.

Jibiri, N.N. and Olowookere, C.J. (2016) Patient dose audit of the most frequent radiographic examinations and the proposed local diagnostic Reference Levels in South-Western Nigeria: imperative for dose optimization. Journal of Radiation Research and Applied Sciences, 9, 274-281.

Johnston, D.A. and Brennan, P.C. (2000) Reference dose levels for patients undergoing common diagnostic examination in Irish hospitals. $\mathrm{Br} . \mathrm{J}$. Radiol. 73, 396-402.

Jones, D.G. and Wall, B.F. (1985) Organ doses from medical examinations using Monte Carlo techniques. NRPB Report. NRPB D-186-1985.

Michael, O.A. Akintayo, D.O., Kofoworola, O.S., Samuel, O.A., Moses, A.A., Helen, B.A. (2016) Assessment of peak kilovoltage accuracy in 10 selected centers in Lagos metropolis, SouthWestern Nigeria: a quality control test to determine energy output accuracy of an generator. J. Health Res. Rev. [serial online], 3, 60-5.

Muhogora, W.E., Ahmed, N.A. and Almosablhi, A., et al. (2008) Patient Doses in Radiographic Examinations in 12 countries in Asia, Africa and Eastern Europe: Initial Results from IAEA Projects. AJR. 190, 1453-1461.

Obed, R.I., Ademola, A.K., Adewoyin, K.A. and Okunade, O. (2007) A doses to patient in routine
X-ray examination of the chest, skull, abdomen and pelvis in 9 selected hospitals in Nigeria. Research Journal of Medical Sciences, 1(4), 209-214.

Ogundare, F.O., Uche, C.Z. and Balogun, F.A. (2004) Radiological parameters and radiation doses of patients undergoing abdomen, pelvis and lumber spine examinations in 3 Nigerian hospitals. Br. $J$. Radiol. 77, 934-940.

Olarinoye, I.O. and Sharifat, I. (2010) A protocol for setting dose reference level for medical radiography in Nigeria. Bayero Journal of Pure and Applied Sciences, 3(1), 138-141.

Oliveria, C., Srpko, M. and Dusko, K. (2005) Fist results on patient dose measurement from conventional diagnostic radiology procedures in Serbia and Montenegro. Radiat. Prot Dosim. 111, 330-335.

Olowookere, C.,J., Babalola, N.N. and Jibiri, N.N., et al. (2012) A preliminary radiation dose audit in some Nigerian hospitals: need for determination of national diagnostic reference levels (NDRLs). The Pacific Journal of Science and Technology, 13(1) 487-495.

Shrimpton, P.C., Wall, B.F. and Jones, D.G., et al. (1986) A National Survey of Doses to patients undergoing a selection of routine exposures in English hospitals. NRPB - R200 (London BMTO).

Tung, C.J., Tsai, H.Y. and Lo, S.H. (2001) Determination of guidance levels of dose for diagnostic radiography in Taiwan. Med. Phys. 28, 850-857.

Veit, R., Bauer, B., Bernhardt, H.J. and Lechel, U. (1998) Proposed procedures for the establishment of diagnostic reference levels in Germany. Radiat. Prot. Dosim. 80, 117-120.

Wall, B.F. (2005) Implementation of dose reference levels (DRLs) in the UK. Radiation Protection Dosimetry, 80, 117-120.

(Received 28/9/2018; accepted 10/3 /2019) 